\title{
Effect of Different Beverages on Colour Stability, Surface Roughness and Surface Hardness of Beauticoat Tooth Surface Coating Material
}

\author{
Gehan G Allam*1, Amr M Abd El Aziz², Dalia I El Korashy³, Mohammed H Al Sakaf ${ }^{4}$ and Mohammed Z \\ Khalifa $^{5}$ \\ ${ }^{1}$ Lecturer Pediatric Dentistry and Dental Public Health Department; Faculty of Dentistry, Ain Shams University \\ ${ }^{2}$ Professor of Pediatric Dentistry and Dental Public Health Department; Faculty of Dentistry, Ain Shams University \\ ${ }^{3}$ Professor of Biomaterials Department; Faculty of Dentistry, Ain Shams University \\ ${ }^{4}$ Assist. Professor of Operative Dentistry and Endodontics Department, Faculty of Dentistry, University of Aden \\ ${ }^{5}$ Lecturer Faculty of Dentistry, University of Aden
}

*Corresponding author: Gehan G Allam, Department of Dental Public Health, Yemen

\begin{abstract}
ARTICLE INFO
Received: 幽 October 01, 2019

Published: 幽 October 15, 2019

Citation: Gehan G Allam, Amr M Abd El Aziz, Dalia I El Korashy, Mohammed $\mathrm{H}$ Al Sakaf, Mohammed Z Khalifa. Effect of Different Beverages on Colour Stability, Surface Roughness and Surface Hardness of Beauticoat Tooth Surface Coating Material. Biomed J Sci \& Tech Res 21(5)2019. BJSTR. MS.ID.003679.
\end{abstract}

Keywords: Aesthetics; Beverages Giomer; Microhardness

\section{ABSTRACT}

Objectives: The aim of this study was to evaluate the effect of immersion in different beverages on the colour stability, the surface roughness and the surface hardness of the tooth-surface coating material

Study Design: 24disc specimens were constructed from giomer tooth surface coating paste. Specimens were immersed in Group 1: Orange Juice. Group 2: Tea. Group 3: Cola. Group 4: Unionized distilled water Specimens were then tested for colour stability using scanning spectrophotometer and for surface roughness using surface roughness tester. A total of 12 disc specimens passed the same immersion cycling were evaluated for microhardness using a Vickers Microhardness tester before storage in the beverages and after cycling the samples in the 4 beverages at 1, 3 months and at 6 months.

Results: tea was associated with the highest color difference followed by cola, orange and then unionized water after 6 months. Cola was associated with the highest change in surface roughness followed by unionized distilled water, orange then tea. Cola was associated with the highest change in surface hardness followed by tea and then orange.

Conclusion: Colour change, surface roughness and surface hardness of Beauticoat were influenced by the beverages used in this study.

\section{Introduction}

Aesthetic problems due to discoloured crowns are common in paediatric clinical practice. The colour and aesthetic appearance of natural teeth has become increasingly important for patients over the last few decades [1]. It is very important to know and understand the cause behind the tooth discoloration and the clinical features of different types of tooth staining in the management of patients with stained teeth, in order to make a correct diagnosis [2]. Unfortunately, it is difficult to achieve aesthetic improvement in young adolescents during their period of growth and development using methods intended for adults [3]. Invention of harmless and temporary tooth surface coating was essential. "Tooth manicure," was one of the first tooth coating materials which improve the colour of teeth in a single day. However, the organic solvents used in nail manicures are difficult to be used inside the oral cavity; and its effect lasts for only 1-2 days, therefore cannot maintain long-term colour improvement [3].

In 2004, White Coat (Kuraray Medical Co., Osaka, Japan) was developed, which is a tooth-coating material for exclusive use in dental clinics. This material uses a self-etching primer, and its adhesion durability is about one month. This product has better 
durability compared to over-the-counter tooth manicures [4,5].Since that Progress has been made for developing material with better durability and good physical properties that cause little damage to the tooth. Surface pre-reacted glass ionomer has been developed, which possesses physical strength and high levels of controlled fluoride release [6,7]. BeautiCoat (Shofu Inc., Kyoto, Japan) tooth surface coating material showed higher fluoride release compared to conventional sealants, thus, this coating material not only covers the affected discoloured surfaces of teeth and achieves aesthetics, but can also contribute to cavity prevention in the surrounding area, or in the neighbouring teeth, which makes it appropriate recommendation to be used as a temporary tooth surface coating treatment for young adolescents with crown discoloration $[7,8]$ To ensure good aesthetics, restorative materials must be resistant to discoloration by staining from food and beverages. The colour stability and staining susceptibility of composites, compomers and glass ionomers have been widely investigated [9-11]. However, there is lack of studies to assess the influence of beverages on the colour stability of tooth coating material [12]. That's why the aim of our study was to evaluate the effect of immersion in different beverages (orange juice, tea, black cola and distilled water) on the colour stability, the surface roughness and the surface hardness of the tooth-surface coating material.

\section{Materials and Methods}

\section{Materials Used}

BeautiCoat $^{\mathrm{TM}}$ (Shofu Inc., Japan) a giomer tooth-surface coating material that contains high levels of controlled-release fluoride, Primer A and B and Meta Echant 37\% phosphoric acid were used for enamel surface treatment. The study was conducted on toothsurface coating material to investigate colour stability, surface roughness and surface hardness. Giomer specimens preparation: A total of 24 disc specimens of diameter and thickness equal to 6 and $2 \mathrm{~mm}$ respectively were constructed from giomer tooth surface coating paste, at room temperature, number coded, then incubated in unionized distilled water at $37{ }^{\circ} \mathrm{C}$, for the initial 24 hours to assure complete polymerization of all samples [12]. A 316 stainless steel matrix, $6 \mathrm{~mm}$ diameter; $2 \mathrm{~mm}$ thickness, was designed and ordered from New Techno_ machine for manufacturing \& Supplies, Egypt, and used for specimen preparation.

\section{Manipulation Procedure}

1. Shade BW2 giomer tooth surface coating material was selected and used for all the specimens to standardize the degree of polymerization.

2. The stainless-steel matrix was placed over and acetate strip which also placed over a microscopic slide.

3. The material was injected into the stainless-steel mold cavity in a single increment.

4. The material /mold assembly was then covered with an acetate strip.
5. In order to compact the material and prevent void and bubble formation, a microscopic slide with a $500 \mathrm{~g}$ weight on it were placed over giomer tooth surface coating material / mold assembly, producing specimens with smooth, highly flat surfaces

6. The weight was removed after one minute. (Figure 1)

7. The material was light cured for 20 seconds through the glass slide, according to the manufacturer's instructions, using a LED light-curing unit (Blue phase C8, Ivoclar Vivadent, USA) with an output intensity of $600 \mathrm{~mW} / \mathrm{cm}^{2}$.

8. The cured disk of Giomer tooth surface coating was removed from the stainless-steel matrix.

9. Gloss Refine* was applied to both disk surfaces, which was then finished and polished with a buffing Super -Snap disks* (Figure 1).

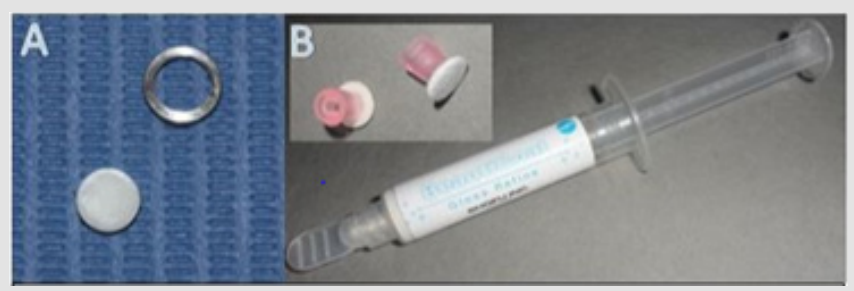

Figure 1.

Immersion procedure: Six specimens from the coating material were made for each type of drink as follow: Group 1: Immersed in Orange Juice. Group 2: Immersed in Tea. Group 3: Immersed in soft drink (Black-Cola). Group 4: Stored in Unionized Distilled Water incubated $*$ in $37{ }^{\circ} \mathrm{C}$ without exposure to a light source (Control Group) (Table 1), (Figure 2) Each specimen was immersed in its solutions for five minutes with agitation, two times a day, with intervals of eight hours [13]. The specimens kept immersed in unionized distilled water at $37^{\circ} \mathrm{C} \pm 1^{\circ} \mathrm{O}$ during the interval between the cycles and changed daily. Specimens were kept in unionized distilled water (for the control group). The drinks were employed in the temperature of consumption, i.e., Orange Juice $\pm 25^{\circ} \mathrm{C}$, Tea $\pm 40^{\circ} \mathrm{C}$ and Black Cola $\pm 4^{\circ} \mathrm{C}$. The temperatures measured with a digital thermometer (Thermo TA-288, UK). These procedures were repeated for 6 months.

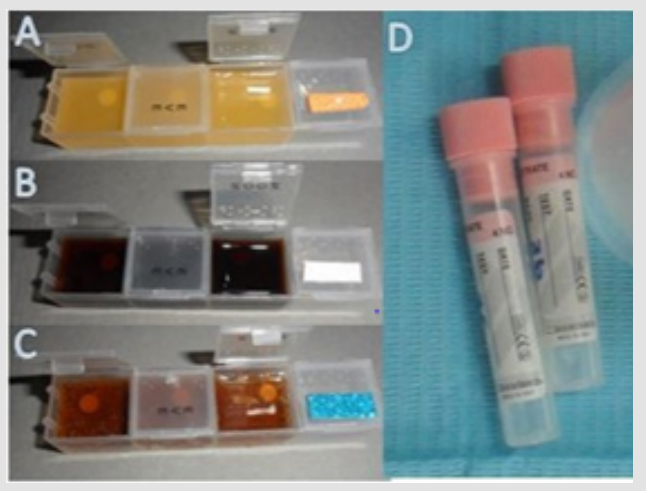

Figure 2.

Table 1: Products used in immersion of the specimens. 


\begin{tabular}{|c|c|c|}
\hline Brand & Manufacturer & Preparation \\
\hline $\begin{array}{c}\text { Lipton, Yellow Label } \\
\text { Tea }\end{array}$ & Unilever S.A.E, Egypt & $\begin{array}{c}\text { Tea bag (2g) } \\
\text { immersed in 200 mg } \\
\text { of boiling water, 2-3 } \\
\text { minutes. }\end{array}$ \\
\hline $\begin{array}{c}\text { Tropicana Orange } \\
\text { Juice Pepsi }\end{array}$ & Beyti IDJ. Egypt & \\
\hline Pepsi & Pepsi Cola, Egypt SAE & \\
\hline Isotonic water & FIPCO, Egypt & \\
\hline
\end{tabular}

\section{Colour Stability Test}

Specimens were tested for colour measurements (zero value) using scanning spectrophotometer, in Photometry Department, National Institute of Standards, Egypt. Values were recorded in International Commission On Illumination (CIE) CIE L*a*b* which is an approximately uniform colour space with coordinates for lightness, namely, white/black (L), red/green (a), and yellow/blue (b) and colour change was calculated from the mean $\Delta \mathrm{L}^{*}, \Delta \mathrm{a}^{*}$, and $\Delta \mathrm{b}^{*}$ values for each specimen. After base line measurements were recorded for all Specimens, change in colour after 1, 3 and 6 months were analysed. Prior to taking measurements, surfaces of the specimens were dried with disposable paper tissue. For each sample, three repeated measurements were taken to determine the colorimetric values i.e. L*(brightness), a* (red-green proportion) and b* (yellow-blue proportion). The differences to the zero value were calculated from the means of the colorimetric values $\Delta \mathrm{L}^{*}, \Delta \mathrm{a}^{*}$ and $\Delta \mathrm{b}^{*}$. The total colour difference $\Delta \mathrm{E}$ for each sample was calculated using the follow- ing equation: $\Delta \mathrm{E}^{*}=\sqrt{(}\left(\Delta \mathrm{L}^{*}\right)^{2}+\left(\Delta \mathrm{a}^{*}\right)^{2}+\left(\Delta \mathrm{b}^{*}\right)^{2}$. The whole procedure was carried out by single laboratory operator and the values were tabulated and subjected to statistical analysis [14]. The effect of immersion in different beverages on the surface roughness of the tooth-surface coating material. The same specimens that were used for colour stability test of the coating material were used for surface roughness. Surface roughness was measured and recorded as the baseline measures by using a surface roughness tester, Laboratory of Biomaterials Department, Faculty of Dentistry, Ain Shams University. The surface roughness of the specimens was re-evaluated at 1 month, 3 months and at the end of 6 months. The whole procedure was carried out by single laboratory operator. The values were tabulated and subjected to statistical analysis [14].

The effect of immersion in different beverages on the surface hardness of the tooth-surface coating material. A total of 12 disc specimens passed the same immersion cycling. Surface microhardness was evaluated using a Vickers Microhardness tester* under $980.7 \mathrm{mN}, \mathrm{Hv} 0.1$ - and 15 -seconds dwelling time in the Solid State Department, National Research Centre, Egypt (Figure 3). Before storage in the beverages, baseline measurements were obtained for each specimen. After cycling the samples in the 4 beverages, surface microhardness of the samples was re-evaluated, as aforementioned; at 1,3 months and at the end of 6 months. The whole procedure was carried out by single laboratory operator. The values were tabulated and subjected to statistical analysis.

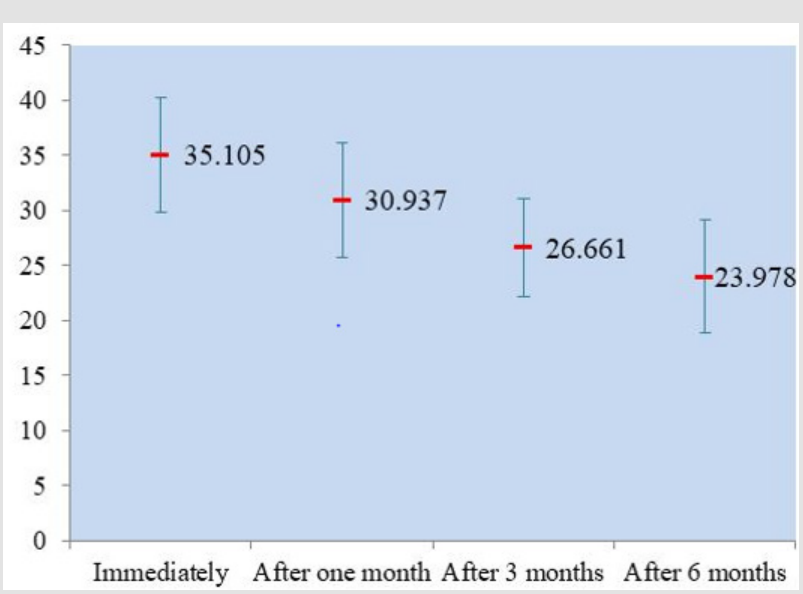

Figure 3: The mean surface micro-hardness during the follow-up period.

\section{Results}

The effect of immersion in different beverages on the colour stability of the giomer tooth-surface coating material: For storage in Orange; the mean $\mathrm{L}^{*}, \mathrm{a}^{*}$ and $\mathrm{b}^{*}$ values were significantly increasing over the follow-up period from a baseline of (78.83) to (83.52) at 6 months for $L^{*}$, from a baseline of (2.03) to (1.73) at 6 months for $\mathrm{a}^{*}$ and from a baseline of (3.13) to (10.52) at 6 months for $b^{*}$. These mean values were significantly differing when compared with the control measures during the same time of follow-up $(p<0.01)$. When storage was in Tea; the mean $L^{*}$ and $b^{*}$ values were significantly decreasing over the follow-up period from a baseline of (78.42) to (68.82) at 6 months for $\mathrm{L}^{*}$ and from a baseline of (3.29) to (-4.32) at 6 months for $b^{*}$. While the mean value of $a^{*}$ was significantly increased and from a baseline of (3.47) to (9.11) at 6 months for $b^{*}$. These mean values were significantly differing when compared with the control measures during the same time of follow-up ( $\mathrm{p}<0.01)$.

When storage was in Cola beverage; the mean $\mathrm{a}^{*}$ and $\mathrm{b}^{*}$ values were significantly increasing over the follow-up period from a baseline of $(-2.07)$ to (8.76) at 6 months for $\mathrm{a}^{*}$ and from a baseline 
of (3.47) to (9.11) at 6 months for $b^{*}$. While the mean $L^{*}$ value was significantly decreasing over the follow-up period from a baseline of (79.50) to (74.16) at 6 months. These mean values were significantly differing when compared with the control measures during the same time of follow-up $(\mathrm{p}<0.01)$. Storing in unionized water (control group); revealed that no significant difference in $\mathrm{L}^{*}$ between immediate immersion and that after 6 months $(117.49$ vs. 117.38). However, there is significant increase in $a^{*}$ value from -2.81 to -1.44 after 6 months and significant decrease in $b^{*}$ value from 4.51 to 3.83 after 6 months. The total color difference after immersion in orange was 1.80 after 1 month, 5.20 after 3 months and 9.53 after 6 months. The total color difference after immersion in tea was 4.13 after 1 month, 9.60 after 3 months and 14.11 after 6 months. The total color difference after immersion in cola was 2.82 after 1 month, 8.63 after 3 months and 13.33 after 6 months. The total color difference after immersion in unionized water was 1.53 after 6 months. (Table 2). The effect of immersion in different beverages on the surface roughness of the Giomer tooth-surface coating material:

Table 2: The total color difference (AE) after storage in different beverages during the study period $(\mathrm{n}=12)$.

\begin{tabular}{|c|c|c|c|c|c|c|}
\hline \multirow{2}{*}{ Color } & After 1 month & & After 3 months & & After 6 months & \\
\hline & $\Delta$ & $\Delta \mathbf{E}$ & $\Delta$ & $\Delta \mathbf{E}$ & $\Delta$ & $\Delta \mathbf{E}$ \\
\hline \multicolumn{7}{|c|}{-Orange } \\
\hline$L^{*}$ & 0.97 & \multirow{3}{*}{1.8} & 2.66 & & 4.69 & \multirow[b]{3}{*}{9.53} \\
\hline $\mathrm{a}^{*}$ & 0.74 & & 2.04 & 5.2 & 3.76 & \\
\hline $\mathrm{b}^{*}$ & 1.33 & & 3.98 & & 7.39 & \\
\hline \multicolumn{7}{|c|}{-Tea } \\
\hline $\mathrm{L}^{*}$ & -2.07 & \multirow{3}{*}{4.13} & -6.19 & & -9.6 & \multirow{3}{*}{14.11} \\
\hline $\mathrm{a}^{*}$ & 3.13 & & 5.31 & 9.6 & 7.01 & \\
\hline $\mathrm{b}^{*}$ & -1.72 & & -5.07 & & -7.61 & \\
\hline \multicolumn{7}{|c|}{-Cola } \\
\hline $\mathrm{L}^{*}$ & -1.16 & \multirow[b]{2}{*}{2.82} & -3.45 & & -5.34 & \multirow[b]{2}{*}{13.33} \\
\hline $\mathrm{a}^{*}$ & 2.26 & & -7.02 & 8.63 & 10.83 & \\
\hline
\end{tabular}

The surface roughness of the coating material in this study was estimated by the mean and standard deviation. It was the least immediately before immersion in different beverages $(0.060$ $\pm 0.011 \mu \mathrm{m})$ and increased to $(0.081 \pm 0.012 \mu \mathrm{m})$ after one month, reaching $(0.097 \pm 0.030 \mu \mathrm{m})$ after 3 months and $(0.545 \pm 0.386 \mu \mathrm{m})$ after 6 months. The one-way ANOVA test showed this trend of incremental increase in surface roughness during the follow-up period to be highly significant $(p<0.001)$. The mean surface roughness before immersion in orange was $0.060 \pm 0.010 \mu \mathrm{m}$. It increased to $0.083 \mu \mathrm{m}$ after 1 month and $0.096 \mu \mathrm{m}$ after 3 months, reaching $0.513 \mu \mathrm{m}$ after 6 months. This increase was not found statistically significant $(p=0.065)$. The mean surface roughness before immersion in tea was $0.050 \pm 0.001 \mu \mathrm{m}$. It increased to $0.073 \mu \mathrm{m}$ after 1 month and $0.093 \mu \mathrm{m}$ after 3 months, reaching $0.260 \mu \mathrm{m}$ after 6 months. This increase was not found statistically significant $(\mathrm{p}=0.136)$. The mean surface roughness before immersion in cola was $0.066 \pm 0.015 \mu \mathrm{m}$. It increased to $0.086 \mu \mathrm{m}$ after 1 month and $0.103 \mu \mathrm{m}$ after 3 months, reaching $0.476 \mu \mathrm{m}$ after 6 months. This increase was found to be highly significant $(p=0.0001)$. The mean surface roughness before storage in unionized distilled water was $0.063 \pm 0.011 \mu \mathrm{m}$ increasing to $0.630 \pm 0.514 \mu \mathrm{m}$ after 6 months. This increase was found to be significant ( $\mathrm{p}=0.043)$.

When comparing the four immersion beverages, cola was associated with the highest change in immediate surface roughness $0.066 \mu \mathrm{m}$ followed by unionized distilled water $0.063 \mu \mathrm{m}$, orange $0.060 \mu \mathrm{m}$ then tea $0.050 \mu \mathrm{m}$ (Table 3). The effect of immersion in different beverages on the surface hardness of the giomer toothsurface coating material: The one way ANOVA test showed this trend of diminution in surface micro-hardness during the followup period to be highly significant $(\mathrm{p}<0.001)$ (Figure 3$)$. The mean surface hardness before immersion in orange was $35.523 \pm$ 4.20VHN. It decreased to 29.676 VHN after 1 month and 28.457 VHN after 3 months, reaching 26.530 VHN after 6 months. This trend was found statistically insignificant $(\mathrm{p}=0.334)$. The mean surface hardness before immersion in tea was 37.096 $\pm 5.65 \mathrm{VHN}$. It decreased to $31.100 \mathrm{VHN}$ after 1 month and 24.247VHN after 3 months, reaching $19.343 \mathrm{VHN}$ after 6 months. This trend was found statistically significant $(\mathrm{p}=0.005)$.

Table 3: The mean surface roughness in urn after immersion in different beverages.

\begin{tabular}{|c|c|c|c|c|c|}
\hline Immersion Beverage & Immediately (n=12) & $\begin{array}{c}\text { After one Month } \\
(\mathbf{n = 9}\end{array}$ & $\begin{array}{c}\text { After three Months } \\
(\mathbf{n = 9})\end{array}$ & $\begin{array}{c}\text { After six Months } \\
(\mathbf{n = 1 2})\end{array}$ & P* \\
\hline Orange & $0.060 \pm 0.010$ & $0.083 \pm 0.015$ & $0.096 \pm 0.050$ & $0.513 \pm 0.392$ & 0.065 \\
\hline Tea & $0.050 \pm 0.001$ & $0.073 \pm 0.011$ & $0.093 \pm 0.032$ & $0.260 \pm 0.208$ & 0.136 \\
\hline Cola & $0.066 \pm 0.015$ & $0.086 \pm 0.011$ & $0.103 \pm 0.011$ & $0.476 \pm 0.081$ & 0.0001 \\
\hline
\end{tabular}




\begin{tabular}{|c|c|c|c|c|c|}
\hline Control & $0.063 \pm 0.011$ & & & $0.630 \pm 0.514$ & 0.043 \\
\hline $\mathrm{P}^{* *}$ & 0.192 & 0.939 & 0.467 & 0.33 & \\
\hline
\end{tabular}

Note: $\mathrm{p}$-values were calculated between the mean values for the same immersion beverage during the follow-up period. $\mathrm{fp}$-values were calculated between the mean roughness after immersion in different beverages at the same time of follow-up. $p$-value $<0.05$ is statistically significant.

The mean surface hardness before immersion in cola was $38.056 \pm 5.91 \mathrm{VHN}$. It decreased to $32.033 \mathrm{HN}$ after 1 month and 27.280VHN after 3 months, reaching 21.113VHN after 6 months. This trend was found statistically significant $(\mathrm{p}=0.014)$. The mean surface hardness before immersion in unionized distilled water (control) was $29.743 \pm 1.42 \mathrm{VHN}$ which decreased to $28.923 \mathrm{VHN}$ after 6 months. This trend was found statistically insignificant $(p=0.535)$. When comparing the four immersion beverages, cola was associated with the highest change in immediate surface hardness (38.056VHN) followed by tea (37.096VHN) and then orange (35.523VHN) (Table 4).

Table 4: The mean surface micro-hardness in VHN after immersion in different.

\begin{tabular}{|c|c|c|c|c|c|}
\hline Immersion Beverage & Immediately (n=12) & After one Month (n=9) & After three Months (n=9) & After six Months (n=12) & P* \\
\hline Orange & $35.523 \pm 4.20$ & $29.676 \pm 6.09$ & $28.457 \pm 6.21$ & $26.530 \pm 6.84$ & 0.344 \\
\hline Tea & $37.096 \pm 5.65$ & $31.100 \pm 5.77$ & $24.247 \pm 2.64$ & $19.343 \pm 1.17$ & 0.005 \\
\hline Cola & $38.056 \pm 5.91$ & $32.033 \pm 5.83$ & $27.280 \pm 4.32$ & $21.113 \pm 2.13$ & 0.014 \\
\hline Control & $29.743 \pm 1.42$ & & & $28.923 \pm 1.54$ & 0.535 \\
\hline P* $^{*}$ & 0.205 & 0.0001 & 0.0001 & 0.042 \\
\hline
\end{tabular}

Note: *p-values were calculated between the mean values for the same immersion beverage during the follow-up period. ${ }^{* *} p$-values were calculated between the mean hardness after immersion in different beverages at the same time of follow-up.p-value $<0.05$ is statistical) sigificant

\section{Discussion}

Currently in Pediatric dental practice, young adolescents are becoming increasingly aware of the aesthetics of their dentition. Tooth discoloration became the most common reason for patient dissatisfaction with their general appearance [15]. Minimal intervention dentistry in the aesthetic management of discolored teeth falls into two main categories of products bleaching and coating agents which are commercially available. This study believed in the coating technology as it appeared to be more convenient with the growing dental structures than the bleaching agents, such as hydrogen peroxide, that could cause significant damage to the soft and hard dental tissues. With the improvement of restorative materials and the demand for aesthetic restorations, giomer has become one of choices for anterior teeth restorations $[16,17]$. It became even more reasonable to select tea, cola and orange as a staining solution in our study since the consumption of these beverages are presumably higher and more prevalent than other beverages in teenage group in the middle east area.

Color stability was investigated, the total color difference after immersion in tea was 4.13 after 1 month where it demonstrated the highest color change among the entire tested tooth surface coating specimens, followed by cola with 2.82 changes in color difference and orange with 1.80 changes in color difference. Measured discoloration effects must always be interpreted relative to their clinical relevance. Assuming $\Delta \mathrm{E} \leq 3.3$ to be clinically acceptable, the tested resin coating materials showed discoloration at or below this threshold value should thus be clinically satisfactory according to many authors [18-21]. Unfortunately, after 3and 6 months all specimens appeared to be extremely stained as the total color difference became higher and again immersion in tea produced the worst scenario, with 14.11 changes in color difference followed by cola then orange with 13.33 and 9.53 changes in color difference respectively. Tooth surface coating specimens showed the least total color change (1.53) after immersion for 6 months in unionized water that could be clinically acceptable, comparable to that the total color difference after immersion for 1 month in orange and cola 1.80 and 2.82 respectively, which also considered clinically accepted. Apart from discoloration of giomer tooth surface coating material in staining solutions, several additional adverse effects such as increase of surface roughness and decrease of micro hardness were investigated. Among all the immersion beverages, the mean surface roughness after immersion in cola was found to be highly significant $(\mathrm{p}=0.0001)$. Surface roughness values started with $0.066 \pm 0.015 \mu \mathrm{m}$ and increased to $0.086 \mu \mathrm{m}$ after 1 month and $0.103 \mu \mathrm{m}$ after 3 months, reaching $0.476 \mu \mathrm{m}$ after 6 months while the mean surface roughness after immersion in unionized water was $0.063 \pm 0.011 \mu \mathrm{m}$ increasing to $0.930 \pm 0.514 \mu \mathrm{m}$ after 6 months. This change was found statistically significant $(p=0.043)$.

These results could be explained by the finding proposed by Habeeb [14], where the giomer filling specimens were placed in artificial saliva for one month, and it was founded that voids formation on the surface of the giomer filing specimens were caused by the dislodged loose surface pre-reacted glass ionomer fillers. The mean surface roughness change were not found statistically significant after immersion in orange and tea even if the mean surface roughness was steadily increased, this could be due to the 
mineral content of the two beverages and the fluoride release and recharge ability of the surface pre-reacted glass ionomer fillers $[22,23]$. Surface micro hardness was also an investigatory step in this study, the mean surface hardness after immersion in cola was associated with marked decrease all through the follow up period followed by tea then orange. There were no available published studies investigating the surface microhardness of the giomer tooth surface coating material.

\section{References}

1. Yamaguchi M, Hisamitsu H, Manabe A (2012) Discoloration of Coating Resins Exposed to Staining Solution-The Influence of Different Surface Conditions. Dental Medicine Research 32(2): 74-80.

2. Watts A, Addy M (2001) Tooth discolouration and staining: a review of the literature. BDJ 190(6): 309-316.

3. Hashimura T, Yamada A, Iwamoto T, Arakaki M, Fukumoto S, et al. (2013) Application of a tooth-surface coating material to teeth with discolored crowns. Pediatric Dental Journal 23: 44-50.

4. Fujita M, Kawakami S, Noda M, Sano H (2006) Color change of newly developed esthetic restorative material immersed in food simulating solutions. Dent Mater J 25(2): 352-359.

5. Manabe A, Kanehira M, Finger WJ, Hisamitsu H, Komatsu M (2009) Effects of opacity and oxygen inhibition of coating resin composites on bond strength to enamel. Dent Mater J 28: 552-527.

6. Ikemura K, Tay FR, Endo T, Pashley DH (2008) A review of chemical approach and ultra-morphological studies on the development of fluoride-releasing dental adhesives comprising new prereacted glass ionomer (PRG) fillers. Dent Mater J 27(3): 315-339.

7. Iwaya I, Mukai Y, Fukukawa H, Teranaka T (2009) Evaluation of ename acid resistance acquired under a temporary esthetic coating material. J Dent HIth 59(9): 125-131.

8. Han L, Okamoto A, Fukushima M (2006) Evaluation of a new fluoridereleasing one-step adhesive. Dent Mater J 25(3): 509-515.

9. Ardu S, Braut V, Gutemberg D, Krejci I, Dietschi D, et al. (2010) A longterm laboratory test on staining susceptibility of esthetic composite resin materials. Quintessence Int 41: 695-702.

10. Ayad N (2007) Susceptibility of restorative materials to staining by common beverages: an in vitro study. Eur J Esthet Dent 2(2): 236-247.

\section{ISSN: 2574-1241}

DOI: 10.26717/BJSTR.2019.21.003679

Gehan G Allam. Biomed J Sci \& Tech Res

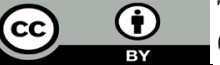

This work is licensed under Creative Commons Attribution 4.0 License

Submission Link: https://biomedres.us/submit-manuscript.php
11. Mundim F, Garcia F, Pires De Souza C (2010) Effect of staining solutions and repolishing on color stability of direct composites. J Appl Oral Sci 18(3): 249-254.

12. Manabe A, Kato Y, Finger W, Kanehira M, Komatsu M, et al. (2009) Discoloration of coating resins exposed to staining solutions in vitro. Dent Mater J 28(3): 338-343.

13. Mundim F, Garcia F, Pires De Souza C (2010) Effect of staining solutions and repolishing on color stability of direct composites. J Appl Oral Sci 18(3): 249-254

14. Habeeb M (2013) The surface roughness of new fluoride releasing material after using three polishing protocols and storage in artificial saliva. J Bagh Coll Dentistry 25(1): 21-26.

15. Tin OM, Saddki N, Hassan N (2011) Factor influencing patient satisfaction with dental appearance and treatments they desire to improve aesthetics. BMC Oral Health 11: 6.

16. Hickel R, Heidemann D, Staehle H, Minnig P, Wilson N (2004) Direct composite restorations: extended use in anterior and posterior situations. Clin Oral Investig 8(2): 43-44

17. Mjör I, Moorhead J, Dahl J (2000) Reasons for replacement of restorations in permanent teeth in general dental practice. Int Dent J 50(6): 361-366.

18. Doray P, Eldiwany M, Powers J (2003) Effect of resin surface sealers on improvement of stain resistance for a composite provisional material. J Esthet Restor Dent 15(4): 244-250.

19. Kolbeck C, Rosentritt M, Lang L, Handel G (2006) Discoloration of facing and restorative composites by UVirradiation and staining food. Dent Mater 22(1): 63-68.

20. Lee Y, Powers J (2007) Combined effect of staining substances on the discoloration of esthetic Class V dental restorative materials. J Mater Sci Mater Med 18(1): 165-170.

21. Villalta P, Lu H, Okte Z, Garcia Godoy F, Powers JM (2006) Effects of staining and bleaching on color change of dental composite resins. J Prosthet Dent 95: 137-142.

22. Honda T, Saku S, Yamamoto K (2004) Study on the film layer produced from S-PRG filler. Jpn J Conserv Dent 47: 391-402.

23. Kamijo K, Mukai Y, Tominaga T, Iwaya I, Fujino F, et al. (2009) Fluoride release and recharge characteristics of denture base resins containing surface pre-reacted glass-ionomer filler. Dent Mater J 28: 227-233. 